\title{
A patient with co-existing bronchial carcinoid tumour and bilateral phaeochromocytoma
}

\author{
HHL Chan, VTF Yeung, CC Chow, GTC Ko, CS Cockram
}

\begin{abstract}
Summary
We report a 31-year-old Chinese man with bronchial carcinoid tumour and bilateral phaeochromocytoma. His sister also gave a history of bilateral carotid body paraganglioma. This case demonstrates the importance of screening for other endocrine disorders in patients with foregut carcinoid tumours.
\end{abstract}

Keywords: bronchial tumour, carcinoid tumour, phaeochromocytoma

\section{Introduction}

Griffiths $^{1}$ first identified the association between duodenal carcinoid, phaeochromocytoma, and neurofibromatosis and proposed that this represented a specific multiple endocrine neoplasia syndrome which he classified as MEN type III a. We now report a patient in whom a bronchial carcinoid tumour coexisted with phaeochromocytoma. There was also a history of bilateral carotid body tumours in a sibling.

\section{Case history}

A 31-year-old Chinese man first developed episodic attacks of tremor, flushing, diarrhoea, and sweating in early 1988. These attacks came on several times a month and lasted 5-10 minutes. In February 1989, he developed haemoptysis and was seen in another hospital. Bronchoscopy indicated a tumour in the right upper lobe bronchus. Right upper lobectomy was performed. Histology showed a $15 \times 10 \mathrm{~mm}$ carcinoid tumour which was neurone-specific enolase and Grimelins positive. The resection margin and three adjacent lymph nodes were clear of tumour. Spot urine for 5-hydroxy indole acetic acid (HIAA) checked after the procedure was not elevated. His symptoms, however, did not improve. Twenty-four hour urine for vanillylmandelic acid (VMA) was then checked and was found to be elevated at $156 \mathrm{nmol} /$ day (normal range 7-85). Magnetic resonance imaging (MRI) of the abdomen revealed bilateral adrenal tumours. There was no sign of liver metastases, or thoracic or pelvic tumours. He was subsequently referred to our unit for further investigation and treatment. His sister had been diagnosed to have bilateral carotid body tumours which were removed in another hos- pital in 1982 and 1985. Histology indicated non-functioning paraganglioma. His father died from oesophageal carcinoma. His mother and two brothers were well but refused further investigation or follow-up.

Clinical examination revealed a right thoracotomy scar. There was no palpable goitre nor skin nodule. Pulse was 80 beats $/ \mathrm{min}$. Blood pressure was $140 / 90 \mathrm{mmHg}$. There was no postural hypotension. The rest of the examination was unremarkable. The results of biochemical investigations are given in the box.

Thyroid ultrasound showed a 7-mm nodule at the lower pole of the right thyroid. Fine needle aspiration cytology was normal. Metaiodo-benzylguanidine scan suggested a region of rather diffuse uptake which was only slightly increased above background in the right upper quadrant of the abdomen and appeared as low-grade liver uptake. MRI of his neck and upper thorax was normal. Venous catheterisation and sampling suggested a noradrenalinesecreting phaeochromocytoma of the right adrenal. The left renal vein could not be catheterized. He was treated with phenoxybenzamine and propanolol in preparation for adrenalectomy.

At operation a $5 \times 2 \times 4 \mathrm{~cm}$ tumour was found on the right adrenal and a $4.5 \times 2 \times$ $3.5 \mathrm{~cm}$ tumour on the left adrenal. Histology confirmed bilateral phaeochromocytoma. No capsular or vascular invasion was seen. He had an uneventful postoperative recovery and was given hydrocortisone and fludrocortisone replacement therapy. A pentagastrin-stimulation test performed subsequently showed normal calcitonin values. He remains well at regular follow-up.

\section{Discussion}

To our knowledge this is the first reported case of a Chinese patient with bronchial carcinoid,

\begin{tabular}{|l|}
\hline Investigations \\
\hline - 24-h urine VMA $130 \mathrm{nmol}$ (normal 0-41) \\
- 24-h urine adrenaline 46-82 nmol (normal \\
9-113) \\
- 24-h urine noradrenaline $10421-14609 \mathrm{nmol}$ \\
(normal 63-146) \\
- normal renal, liver and thyroid function \\
- normal serum calcium and phosphate levels \\
normal dexamethasone suppression test
\end{tabular}


phaeochromocytoma, and a family history of paraganglioma. Interestingly, neither he nor any member of his family has evidence of neurofibromatosis. The coexistence of these neuroendocrine tumours is unlikely to be coincidental.

Lubarsch $^{2}$ first described a carcinoid tumour in 1888. In 1962, Williams ${ }^{3}$ classified carcinoid according to embryologic origin into derivatives of foregut (thymus, bronchus, stomach, and duodenum), midgut and hindgut (jejunum, ileum, appendix, colon, and rectum). Most reported carcinoid series ${ }^{4-6}$ indicate foregut carcinoids to be less common than midgut- and hindgut-derived carcinoids, accounting for less than $20 \%$ of all carcinoids. On the other hand, in patients with carcinoid tumours and other endocrine tumours, the carcinoid tumours are usually of foregut origin. ${ }^{4,5}$ Foregut carcinoids can produce a variety of hormones such as ACTH and somatostatin. In addition to the difference in anatomical distribution, there is also a difference in sexual predominance. Carcinoids not associated with other endocrine tumours are evenly distributed between men and women. In patients with other associated endocrine tumours, bronchial carcinoids are more common in women $(79 \%)$ and tend to be benign while more men $(88 \%$ ) have thymic carcinoids which are usually malignant. ${ }^{6}$

Underdahl ${ }^{7}$ was the first to note the presence of a bronchial carcinoid in a patient with MEN type I. Since then other reports have emerged to support the linkage. ${ }^{8-10}$ In 1965 , Barnard and Johnson reported a case of malignant phaeochromocytoma and duodenal carcinoid. ${ }^{11}$ More recently, Griffiths suggested that the association between duodenal carcinoid, phaeochromocytoma and neurofibromatosis forms a distinctive neuroendocrine syndrome which he classified as type III a. ${ }^{12}$ On the other hand, paraganglioma has been associated with carcinoid tumour and neurofibromatosis. ${ }^{13}$

1 Griffiths DFR, Williams GT, Williams ED. Multiple endocrine neoplasia is associated with Von Recklinghausen's disease. $B M F$ 1983; 28: 1341-3.

2 Lubarsch $O$. Uber den primaren krebs des ileum nebst Bernerkungen uber das gleichzeitige Vorkommen von Krebs and Tuberculose. Virchows Arch 1888; 111: 281-317.

3 Williams ED. The classification of carcinoid tumours. Lancet 1963; 1: 238-9.

4 Manes JL, Taylor HB. Thymic carcinoid in familial multiple endocrine adenomatosis. Arch Pathol Lab Med 1973; 95: ple endoci.

5 Weichert RF. The neural ectodermal origin of the peptide secreting endocrine glands: a unifying concept for the etiology of multiple endocrine adenomatosis and the inappropriate secretion of peptide hormones by nonendocrine tumours. Am $\mathcal{F}$ Med 1970; 49: 232-41.

6 Duh QY, Hybarger CP, Geist R, et al. Carcinoids associated with multiple endocrine neoplasia syndromes. Am $\mathcal{f}$ Surg 1987; 154: 142-8

7 Underdahl LO, Woolner LB, Black BM. Multiple endocrine adenomas: report of 8 cases in which the parathyroids, pituitary and pancreatic islets were involved. $\boldsymbol{f}$ Clin Endocrinol 1953; 13: 20-47.

8 Fisher ER, Hick J. Further pathologic observation on the syndrome of peptic ulcer and multiple endocrine tumours. Gastroenterology 1960; 38: 458-66.

9 Rosai J, Higa E. Mediastinal endocrine neoplasm, of probable thymic origin, related to carcinoid tumour: clinicopathologic study of 8 cases. Cancer 1972; 29: 1061-74.
Multiple endocrine neoplasia type I

Wermers' syndrome

autosomal dominant

parathyroid adenoma

+ pituitary adenoma (prolactin, growth

hormone)

+ pancreatic endocrine tumour

\section{Multiple endocrine neoplasia type II}

Sipple's syndrome

autosomal dominant

parathyroid adenoma

+ phaeochromocytoma

+medullary carcinoma of the thyroid

The predominance of foregut carcinoid may be embryologically associated with the development of multiple endocrine neoplasia. Histological evidence suggests that bronchial carcinoid, phaeochromocytoma, and paraganglioma are tumours of the peripheral nervous tissues. Although bronchial carcinoid derives from Kultchitskey cells of bronchial epithelium, ${ }^{14,15}$ histologically, it can be almost identical to phaeochromocytoma and paraganglioma which arises from the chromaffin cells. ${ }^{16}$

The causes of these neuroendocrine tumours have not been well established. Stephen ${ }^{13}$ proposed the possibility of production of a local nerve-derived trophic factor in the pathogenesis of these tumours, whereas Griffiths ${ }^{12}$ suggested a genetic defect leading either to a production of a circulating growth-stimulating substance or to an abnormality of the intracellular growth-control mechanisms rendering the cells more likely to develop neoplasia. There is, however, no evidence of racial differences in the incidence of these tumours.

10 Rosai J, Higa E, Davie J. Mediastinal endocrine neoplasm in patients with multiple endocrine adenomatosis: a previously unrecognized association. Cancer 1972; 29: 1075-83.

11 Barnard PJ, Jacobson L. Malignant phaeochromocytoma associated with argentaffinoma and hypotensive crises: report of a case. Cent Afr 7 Med 1965; 11: 185-90.

12 Griffiths DFR, Williams GT, Williams ED. Duodenal carcinoid tumours, phaeochromocytoma, and neurofibromatosis, islet cell tumour, phaeochromocytoma and matosis, islet cell tumour, phaeochromocytoma and the Von Hippel-Lindau Complex: two distinctive

13 Syndrome. $Q \mathcal{F}$ Med 1987; 64: 769-82. Stephens M, Williams GT, Jasari B, Williams ED. Syn-
chronous duodenal neuroendocrine tumours in Von Reckchronous duodenal neuroendocrine tumours in Von Reck-
linghausen's disease - a case report of co-existing ganglinghausen's disease - a case report of co-existing gang-
liocytic paraganglioma and somatostatin-rich glandular carliocytic paraganglioma and somatostatin-rich

14 Bensch KG, Gordon GB, Miller LR. Electron microscopic and biochemical studies on the bronchial carcinoid tumour. Cancer 1965; 18: 592-602.

15 Gmelich JT, Bensch KG, Liebow AA. Cells of Kultchitsky type in bronchioles and their relation to the origin of peripheral carcinoid tumour. Lab Invest 1967; 17: 88-98.

16 El-Salhy M, Lundqvist M, Wilander E. Bronchial carcinoids and phaeochromocytoma. APMIS 1986; A: 22935. 